\title{
|PARA QUE NÃO SE ESQUEÇA: DIREITO FUNDAMENTAL À MEMÓRIA E A CONTRIBUIÇÃO DA FORMAÇÃO ESCOLAR
}

\author{
SO THAT YOU DO NOT FORGET: THE FUNDAMENTAL RIGHT TO MEMORY AND THE \\ CONTRIBUTION OF SCHOOL EDUCATION
}

Priscila Pinheiro ${ }^{1}$

Gilsilene Passon P. Francischetto ${ }^{2}$

\begin{abstract}
Resumo: A sociedade brasileira é formada por diversas marcas adquiridas por processos de violação de direitos e de cometimento de atrocidades por parte do Estado. O presente estudo tem por objetivos a análise da memória enquanto um direito fundamental e os mecanismos criados pela Constituição Federal de 1988, como o art. 216, o qual confere a proteção estatal ao patrimônio cultural brasileiro e o art. 68 do Ato das Disposições Constitucionais Transitórias, que garante aos remanescentes quilombolas a propriedade definitiva das terras que estejam ocupando. Utilizarse-á a pesquisa bibliográfica para a análise dos conhecimentos primários, a partir da aplicação do método dedutivo, o qual partirá de premissas, maior e menor, para se chegar à conclusão. Para tanto, analisar-se-á a necessidade do conhecimento, pelas gerações futuras, da verdade sobre o passado histórico como medida de não repetição de abusos cometidos, por exemplo, pelo Estado, sendo elas responsáveis pela transformação social. Por último, apresentar-se-á alguns mecanismos de implantação da memória no ambiente escolar como forma de resgatar de maneira significativa, para o aluno, os fatos históricos.
\end{abstract}

Palavras-chave: Direito fundamental. Memória. Ditadura Militar. Formação escolar. História.

\begin{abstract}
The Brazilian society is formed by several brands acquired by processes of violation of rights and atrocities committed by the State. The present study aims to analyze memory as a fundamental right and the mechanisms created by the Federal Constitution of 1988, as art. 216, which grants state protection to Brazilian cultural heritage and art. 68 of the Transitional Constitutional Provisions Act, which guarantees the remaining quilombolas the definitive ownership of the lands they occupy. In order to do so, we will analyze the need for future generations to know the truth about the historical past as a measure of non-repetition of abuses committed, for example, by the State, which are responsible for social transformation. Finally, some mechanisms for the implementation of memory in the school environment will be presented as a way of meaningfully recovering the historical facts for the student.
\end{abstract}

Keywords: Fundamental right. Memory. Military dictatorship. School education. History.
Recebido em 30 de novembro de 2017

Avaliado em 14 de agosto de 2018 (AVALIADOR A) Avaliado em 18 de outubro de 2019 (AVALIADOR B) Aceito em 19 de outubro de 2019

\footnotetext{
Doutora em Direitos e Garantias Fundamentais pela Faculdade de Direito de Vitória; Professora Adjunta A na Universidade Federal do Mato Grosso do Sul; CPAN - Campus do Pantanal, Unidade I - Avenida Rio Branco, 1270, Universitário, 79304902, Corumbá, Mato Grosso do Sul, Brasil; https://orcid.org/0000-0002-0452-5344; priscilatinelli@hotmail.com

2 Pós-doutora pelo Centro de Estudos Sociais da Universidade de Coimbra, Portugal; Professora Titular na Graduação, Pós-graduação, Mestrado e Doutorado da Faculdade de Direito de Vitória; https://orcid.org/0000-0002-5515-5881; gilsilenepasson@uol.com.br
} 


\section{Introdução}

Ao longo da história da sociedade brasileira, ocorreram inúmeras lutas sociais, transições de governos, repressões políticas, crises econômicas que, por vezes não são do conhecimento de todos, mas apenas daqueles que vivenciaram determinado contexto histórico ou o repassaram, por meio de relatos, para seus familiares e conhecidos.

Diante de tantos acontecimentos históricos, muitas gerações permaneceram passivas em decorrência do completo desconhecimento do contexto social, que culminou com participações populares frente aos atos dos governantes. A todo esse conhecimento dá-se o nome de memória, a qual é construída pelas lembranças dos indivíduos que vivenciaram de perto os fatos no decorrer da história e pelos registros históricos compostos pelos documentos, jornais da época, memoriais, livros, dentre outros.

Nesse sentido, é importante que a memória histórica seja retomada, por meio de narrativas de testemunhas daquela época, por exemplo, pois o que se tem nos livros didáticos é apenas a visão dos historiadores, o que não nos fornece uma memória integral. Desta forma, deve haver o conhecimento das várias versões do mesmo fato, pois a verdade que se busca não é somente aquela baseada nos relatos de testemunhas e nem somente aquela construída pela visão dos historiadores, de maneira que uma não deve prevalecer frente à outra, mas ambas devem coexistir para que haja o conhecimento mais amplo das variadas interpretações sobre determinado fato.

Tomando por base estas questões, o presente trabalho tem como objetivos a discussão da influência do incentivo à formação de uma consciência crítica na educação no que tange à retomada dos acontecimentos do passado, descrever a importância da reconstrução de fatos históricos durante a formação escolar e, por último, apresentar alternativas que viabilizem a inclusão do direito à memória no âmbito da escola.

Como metodologia de pesquisa, pretende-se utilizar a pesquisa bibliográfica como fonte de conceitos essenciais para a construção de um conhecimento capaz de promover uma análise crítica acerca do tema proposto, assim buscar-se-á fontes secundárias especialmente publicações como livros, estudos acadêmicos, artigos que abarquem a questão.

Para tanto, será utilizado o método dedutivo, o qual "[...] tem o propósito de explicar o conteúdo das premissas [...] os argumentos dedutivos ou estão corretos ou incorretos [...]" (LAKATOS; MARCONI, 2004, p. 74). Na metodologia adotada, extrai-se uma conclusão lógica a partir de uma premissa menor e de uma premissa maior. Ou seja, utiliza-se a dedução a fim de chegar a uma conclusão por meio de premissas.

Assim, o presente trabalho destina-se à análise do ambiente escolar como o lugar adequado para promover essa conscientização crítica e a retomada da memória, já que a escola possui uma parcela significativa de responsabilidade no que tange à formação dos indivíduos. Portanto, o exame 
da estrutura escolar atual juntamente com a análise da memória como um direito fundamental serão essenciais para a construção da identidade nacional.

\section{0 legado da memória na sociedade contemporânea e seu status de direito fundamental}

Para se discutir a fundamentalidade do direito à memória é preciso analisar os direitos fundamentais, ou seja, compreender o seu significado, além do tratamento conferido a eles, no Brasil, e, por fim, a sua finalidade perante o Estado Democrático de Direito. Nesse sentido, Dimoulis e Martins (2011, p. 49) apresentam o seguinte conceito de direitos fundamentais:

direitos fundamentais são direitos público-subjetivos de pessoas (físicas ou jurídicas), contidos em dispositivos constitucionais e, portanto, que encerram caráter normativo supremo dentro do Estado, tendo como finalidade limitar o exercício do poder estatal em face da liberdade individual.

A partir da definição apresentada, extrai-se que para ser classificado como direito fundamental é preciso que seja inserido no texto constitucional, o que seria um aspecto formal do conceito. Deste modo, somente atingiria o status de fundamental aquele direito que fosse reconhecido como tal pelo Estado e, como consequência desse reconhecimento, passasse a compor o rol de direitos fundamentais da Constituição Federal. Por outro lado, há o aspecto material, o qual consiste na limitação ao poder estatal em face da liberdade individual, conforme descrito no conceito exposto.

Diante disso, pode-se afirmar, que o reconhecimento de um direito como fundamental é imprescindível para a construção de uma ordem democrática e, nesse sentido, destaca-se que para ser positivado na Constituição Federal, o direito precisa refletir a necessidade da sociedade na qual ele está inserido, já que o texto constitucional é considerado "[...] o espelho do legado cultural de um povo, e explicita o seu modo específico de existência." (DANTAS, 2010, p. 37).

Além disso, os direitos fundamentais constituem os principais valores de uma sociedade, que em decorrência dessa característica foram expressamente previstos na Carta Magna. Porém, vale ressaltar, que o rol previsto no texto constitucional não é taxativo, ou seja, não esgota a previsão dos direitos fundamentais, já que por representarem as necessidades da sociedade variam de acordo com o contexto vivenciado pela mesma.

Partindo do pressuposto de que os direitos são classificados como fundamentais e, posteriormente, positivados na Constituição Federal, então, a partir da necessidade de cada nova sociedade surge a discussão acerca da importância de se considerar a memória como um direito do povo e, além disso, elevá-lo ao status de fundamental. Em primeiro lugar, é importante salientar que há dois tipos de memória, quais sejam a individual e a coletiva. 
Por memória individual, entende-se que ela se consiste na "[...] capacidade que cada ser humano possui de guardar as experiências vividas e/ou transmitidas, possibilitando o aprendizado e o aperfeiçoamento de objetos e dos modos de fazer e de viver." (DANTAS, 2010, p. 52). Por outro lado, a memória coletiva pode ser definida como "[...] o processo seletivo de retenção e utilização contínua de ideias, impressões, imagens, conhecimentos e experiências adquiridas e vividas anteriormente." (DANTAS, 2010, p. 52).

Com base nessas definições, compreende-se que a memória constitui a lembrança do passado, seja aquele vivenciado pelo próprio indivíduo, que se resume na memória individual ou aquele protagonizado por toda a sociedade em um contexto histórico anterior, o qual perfaz a memória coletiva. Importante ressaltar, que aqui trabalharemos com a defesa da memória coletiva, ou seja, aquela que influencia diretamente para a formação de um Estado Democrático, pois há transparência nos acontecimentos pretéritos, principalmente, no que tange aos motivos que acarretaram tais fatos, o que se resume na verdade real dos fatos.

Acerca disso, Barbosa e Vannuchi (2009, p. 55) defendem que "a democracia, para que efetivamente se consolide, necessita, portanto, que os povos conheçam toda a verdade sobre o seu passado, como forma de aprendizado, para modificar o presente e gerar um futuro de paz." Assim, fala-se da memória como um direito em decorrência do fato de que as novas gerações têm a necessidade de conhecer o passado de seu país, visto que por muito tempo a sociedade brasileira foi vítima dos arbítrios do Poder Público e a verdade quanto a esses fatos nem de longe foi transmitida de forma integral à população. Portanto,

a integridade e revelação do conteúdo dos registro históricos, especialmente naqueles países, como o Brasil, passaram por um processo de transição política, é fundamental para consolidação do regime democrático e para proteção dos direitos individuais e coletivos. (SAMPAIO; ALMEIDA, 2009, p. 261).

Isso ocorre, sobretudo, face à postura do Estado e das autoridades no sentido de que transmitem ao povo aquilo que lhes é conveniente contando, assim, a sua versão dos fatos, a qual é titularizada como memória oficial. Acerca dessa memória oficial, afirma-se que ela

[...] consiste na construção de uma sucessão de fatos "históricos", tidos como importantes para o desenvolvimento do Brasil, para fornecer um quadro de referências à memória coletiva, delimitando-a, justificando-a e organizando-a. com isso, pretende-se a sua aceitação pelos indivíduos e pela sociedade, que passa a ter uma origem e um destino comum, reforçando o sentimento de pertença dos indivíduos ao grupo, condição sine qua non de sua coesão interna, além de demarcar as fronteiras (territoriais e sociais) entre grupos diversos. (DANTAS, 2010, p. 56).

De acordo com a premissa de que a verdade e a memória são direitos e, sobretudo, necessidades do povo, é preciso que haja uma segurança maior quanto a elas, de forma que a 
positivação de tais institutos é imprescindível para a luta do povo frente ao esquecimento das lutas e conquistas sociais. Nesse momento é que surge a importância de se elevar o direito à memória ao status de fundamental, uma vez que, a partir deste ato, o Estado terá um obstáculo concreto à camuflagem da verdade dos acontecimentos e o dever de proporcionar o conhecimento amplo das suas práticas frente à sociedade.

Outro ponto que embasa tal premissa é o fato de que "a memória social é pública, e por ser compartilhada consegue sobreviver aos indivíduos, transcendendo-os." (DANTAS, 2010, p. 55). Ou seja, com a publicidade da memória, é possível que a história seja repassada às futuras gerações, de forma a evitar a alienação acerca dos fatos que levaram à conquista de uma sociedade democrática e a construção de um governo que começasse a respeitar os direitos coletivos e sociais. Diante disso, pode-se descrever, que:

Os debates trazidos à cena reflexiva procuram sublinhar a importância da organização da cidadania, na sociedade civil, para que aconteçam interrupções sequenciais nas instâncias de dominação, como as esferas do poder, e em todos os âmbitos organizativos que impeçam a autonomia da razão e o protagonismo dos sujeitos que lutam pela Verdade como condição de Justiça. (PIRES, 2015, p. 62).

Neste diapasão, constitui uma das características da democracia o livre acesso às informações e aos atos praticados pelo Poder Público, por isso, diz-se que "todo governo democrático deve, portanto, assegurar o livre acesso à informação, prestando contas de seus atos à cidadania." (BARBOSA; VANNUCHI, 2009, p. 59).

Não se deve impedir somente que essa história caia no esquecimento, mas sobretudo as suas vítimas não sejam esquecidas, porque as violações da humanidade dizem "[...] respeito à totalidade, aos humanos que habitam o planeta e gozam do direito em conjunto. $\bigcirc$ humano, a espécie, o sujeito do direito solidário, sente-se ofendido pelo desacato cometido em local específico a uma pessoa específica." (PIRES, 2015, p. 62).

Deste modo, faz-se necessária a perpetuação desses acontecimentos por meio da transmissão da história a cada geração, porém isso somente será possível com o conhecimento das lutas sociais que culminaram na construção de uma democracia. Assim, " [...] direito à verdade rompe com o pacto do silêncio e com uma injustiça continuada. Lança luzes à dimensão sombria de nossa história, na defesa dos direitos à justiça, à verdade e à memória individual e coletiva." (BICUDO; PIOVESAN, 2006).

É preciso levar em consideração que, uma sociedade, que conhece o seu passado é capaz de evitar o cometimento de erros no futuro, o que condenaria as próximas gerações à repetição das atrocidades vivenciadas no passado. Deste modo, o direito fundamental à memória serviria como um instrumento capaz de construir uma consciência coletiva sobre uma base de lembranças, a qual possibilitaria qualquer ação social no presente ou mesmo no futuro (OST, 2005, p. 50). 
Além disso, a falta de uma memória viva causa grandes estragos em um povo, já que o maior obstáculo está justamente no tempo, o qual acarreta prejuízos para a construção da história, haja vista que a mesma passa por um processo de esquecimento e, deste modo, "sem memória, uma sociedade não se poderia atribuir uma identidade." (OST, 2005, p. 42). Por isso é que, um povo tem que manter sua história viva e ao alcance de todos.

Luta-se, portanto, por um novo conceito de história capaz de reconhecer as barbáries cometidas, ao contrário de uma visão comum da "[...] história triunfante e impiedosa do progresso, que contabiliza sua destruição como um custo aceitável da sua marcha incessante." (SILVA FILHO, 2008, p. 157-158).

A importância da memória, dentre outros fatores, é justamente para a formação de um sentimento de repulsa por atos praticados pelo Poder Público com o fim de reprimir aqueles que contrariavam suas determinações. Isso porque os efeitos do esquecimento são devastadores, tendo a capacidade de desvincular a realidade da reflexão, uma vez que "os acontecimentos podem repetir-se e vitimarem a humanidade novamente, e a ausência de uma compreensão sistêmica do passado, a crítica não realizada a respeito do que nos foi legado como herança, pode levar a um novo aniquilamento." (PIRES, 2015, p. 69).

Para demonstrar a necessidade do sentimento de repulsa e da construção de uma história contada pelas narrativas das próprias vítimas do progresso, Silva Filho (2008) correlaciona a figura do "angelus novus" de Walter Benjamin à sociedade marcada pela indiferença e omissão. Para o autor,

a figura do anjo traz, ao mesmo tempo, a ideia de salvação e de fraqueza, de redenção e de impotência, de liberdade e de aprisionamento. O olhar do anjo é o olhar das vítimas da história, horrorizado diante das ruínas, pois, para ele, os escombros são o resultado de um evento único, tão singular quanto a particularidade irrepetível das suas vítimas. (SILVA FILHO, 2008, p. 159).

Recuperar a memória significa, então,

[...] trazer ao presente o passado, aquele que ficou ausente. É no cultivo e no resgate dessa e de todas as histórias negadas pelo avanço impiedoso da civilização que se poderá ser capaz de se tornar mais humano, de voltar a se indignar com as injustiças e de não esquecer a barbárie que se esconde por trás de cada cena da vida cotidiana. (SILVA FILHO, 2008, p. 173).

Não se está afirmando, neste sentido, que a memória vai garantir a não repetição de atrocidades pela humanidade, pois ela não tem todo esse poder. Trata-se de um caminho importante, visto que tem a função de fazer a sociedade repensar pelo fato de que traz à tona um passado não vitorioso, mas que deixou profundas marcas, especialmente, em sociedades que tiveram experiência de governos autoritários e repressivos. 
Apesar de todas essas considerações, não basta a implantação do direito à memória no rol dos direitos fundamentais da Carta Magna, sem que haja, em contrapartida, uma atuação positiva do Estado em prol de garantir a sua efetivação. Deste modo, "o que é exigido dos Estados é a completa e imparcial análise dos fatos e fidedigna disseminação da informação que está sob seu poder." (SAMPAIO; ALMEIDA, 2009, p. 267). Portanto, o Poder Público "deve garantir que a questão seja amplamente averiguada e que os resultados da investigação se tornem públicos, independentemente de o resultado obtido agradar ou desagradar os agentes estatais." (SAMPAIO; ALMEIDA, 2009, p. 267).

É o caso, por exemplo, da implantação da Justiça de Transição, cujos pilares são: a justiça, a verdade, a reparação, as reformas institucionais e a reconciliação. Muito comum nas sociedades que sofreram supressão de direitos por regimes autoritários, como é o caso do Brasil, no período da ditadura militar, o processo transicional é um importante mecanismo de resgate da memória. Para além da questão de violações de direitos por parte do Estado, o texto constitucional de 1988, como o marco do processo de redemocratização no país, traz outros elementos que se relacionam com esta busca pela memória na sociedade brasileira.

\section{0 legado da memória e sua previsão na Constituição Federal de 1988}

Acerca das atitudes concretas do Estado no que tange ao resgate da memória, identifica-se algumas previsões contidas no texto constitucional de 1988, como o art. 216, que traz o conceito de patrimônio cultural e lhe confere a respectiva proteção. Segundo o Texto Constitucional, "constituem patrimônio cultural brasileiro os bens de natureza material e imaterial, tomados individualmente ou em conjunto, portadores de referência à identidade, à ação, à memória dos diferentes grupos formadores da sociedade brasileira [...]" (BRASIL, 1988). De acordo com Dantas (2010, p. 114), o patrimônio cultural é fruto da análise de 3 conceitos basilares, que são: os bens culturais, a cultura e o patrimônio cultural em si.

Nesse sentido, é importante descrever que o patrimônio cultural é a manifestação da cultura de um povo e esta, por sua vez, pode ser definida "[...] como as diferentes maneiras de viver de um povo, transmitidas de geração a geração recebidas por tradição, bem como o modo de falar, as crenças, o saber e o artesanato representam a forma do homem se relacionar em sociedade." (MAIA, 2003, p. 39). Portanto, a cultura é todo o arcabouço histórico que individualiza e, ao mesmo tempo, identifica um povo.

Com relação aos bens culturais, pode-se depreender que estes são "[...] os elementos heterogêneos que compõem a Cultura e são identificados porque indivíduos ou grupos sociais conferem-lhes algum tipo de valor, capaz de torná-los importante e aptos ao reconhecimento e à proteção." (DANTAS, 2010, p. 114). Esses bens culturais retratam a diversidade de culturas, ou seja, cada grupo social, étnico, econômico teve, ao longo da história, a sua contribuição, o que culminou na composição do patrimônio cultural, o qual merece a sua proteção por parte do Poder Público. 
Ainda com relação aos bens culturais, é importante destacar a definição atribuída pela Convenção de Haia (1954) aos bens titulares de tal característica, qual seja:

Para fins da presente Convenção são considerados como bens culturais, qualquer que seja a sua origem ou o seu proprietário:

a) Os bens, móveis ou imóveis, que apresentem uma grande importância para o patrimônio cultural dos povos, tais como os monumentos de arquitectura, de arte ou de história, religiosos ou laicos, ou sítios arqueológicos, os conjuntos de construções que apresentem um interesse histórico ou artístico, as obras de arte, os manuscritos, livros e outros objectos de interesse artístico, histórico ou arqueológico, assim como as colecções científicas e as importantes colecções de livros, de arquivos ou de reprodução dos bens acima definidos;

b) Os edifícios cujo objectivo principal e efectivo seja, de conservar ou de expor os bens culturais móveis definidos na alínea a), como são os museus, as grandes bibliotecas, os depósitos de arquivos e ainda os refúgios destinados a abrigar os bens culturais móveis definidos na alínea a) em caso de conflito armado;

c) Os centros que compreendam um número considerável de bens culturais que são definidos nas alíneas a) e b), os chamados "centros monumentais". (ORGANIZAÇÃO DAS NAÇÕES UNIDAS PARA A EDUCAÇÃO, A CIÊNCIA E A CULTURA, 2017).

E o terceiro conceito, que é do próprio patrimônio cultural, resume-se ao "[...] conjunto formado por esses bens culturais, valorados pela sociedade, que assume um conteúdo e um perfil diferenciado consoante cada contexto social e histórico." (DANTAS, 2010, p. 115). Com base nessa transcrição, podemos afirmar, que o patrimônio cultural é o reflexo do contexto histórico protagonizado por cada tipo de sociedade, o qual mesmo tendo ocorrido no passado tem forte influência no presente e no futuro motivo este, que evidencia a necessidade de conservação deste patrimônio.

A própria caracterização do patrimônio cultural foi reformulada, pois somente com o advento da Constituição Federal de 1988, o rol passou a ser exemplificativo, ou seja, deixou a cargo da Administração Pública a proteção tanto de bens de natureza material quanto de imaterial, o que é mais fácil de se adequar à natureza multidimensional das culturas atuais.

Apesar de toda essa evolução em matéria de proteção constitucional aos bens culturais, ainda é preciso avançar, pois para que o patrimônio cultural se efetive como um fundamento do direito à memória é necessário que a sociedade tome "[...] consciência do seu papel fundamental de guardiã do próprio patrimônio, passando então a impedir a degradação e a destruição do meio ambiente, imóveis e objetos culturais, numa ação de salvaguarda preventiva." (MAIA, 2003, p. 41).

Trata-se de uma herança deixada pelo passado àqueles que não puderam vivenciá-lo. Assim, toda essa riqueza não deve ser perdida com o passar do tempo, o qual contribui para a deterioração das construções, no caso dos bens materiais, e para o esquecimento, no caso dos imateriais. Além de um dever do Poder Público, a preservação do patrimônio cultural é um direito da comunidade, a qual necessita do conhecimento da sua história e "[...] pretende ver conservada a memória de fatos e valores culturais da nação brasileira." (MAIA, 2003, p. 41). 
Nesta perspectiva, "preservar o patrimônio nacional é dever do Estado e direito da comunidade, que pretende ver conservada a memória de fatos e valores culturais da nação brasileira." (MAIA, 2003, p. 39). Além disso, "é sabido que todo o ato de preservação de patrimônios culturais traz consigo a ideia de que é preciso salvar algo que está em perigo de desaparecimento ou se quer tirar do silêncio e do esquecimento." (ABREU; MATTOS, 2012).

Assim, a proteção que deve ser conferida aos bens públicos vai muito além do tombamento, sendo este apenas um dos instrumentos de proteção. Acerca disso, Maia (2003, p. 40) afirma que

não se entenda por preservação apenas o ato do tombamento. Preservar é conservar a memória, portanto conceito genérico que dá ao Poder Público o direito de, conforme a legislação, exercer todas as atividades administrativas indispensáveis ao fomento de ações de preservação, sem ferir direitos individuais.

O tombamento, por sua vez, é um instituto jurídico muito utilizado pelo Poder Público na preservação dos bens culturais, pois confere proteção sem retirar a propriedade do particular. Apesar de o particular continuar com a propriedade do bem, lhe são impostas algumas restrições quanto ao uso e a conservação do mesmo a fim de manter na íntegra aquela edificação, o que retrataria de forma mais fidedigna aquele momento histórico.

Além da proteção ao patrimônio cultural pela Constituição Federal de 1988, pode-se verificar outra forma de resgate da memória por meio do Ato das Disposições Constitucionais Transitórias, cujo art. 68 dispõe que "aos remanescentes das comunidades dos quilombos que estejam ocupando suas terras é reconhecida a propriedade definitiva, devendo o Estado emitir-lhes os títulos respectivos." (BRASIL, 1988).

Com relação ao surgimento da necessidade de preservação do patrimônio cultural brasileiro juntamente com o reconhecimento da propriedade das comunidades quilombolas, é importante descrever, que o Estado teve a preocupação com a formação da identidade nacional, a qual está intimamente ligada à manutenção das construções históricas, documentos, culturas tradicionais, dentre outros.

Nesse sentido, está a afirmação de Ramos, a qual considera que a Constituição de 1934, marco inicial da preservação do patrimônio histórico, juntamente com a Constituição de 1988, cujo texto inovou ao assegurar o direito de propriedade das comunidades quilombolas, marcaram uma transição na postura do Estado face a cultura dos grupos tradicionais, bem como a história da própria sociedade brasileira. Para a referida autora, o Poder Público entendeu, na elaboração dessas constituições, a necessidade de preservação da memória e, sobretudo, de formação da identidade nacional. Desta forma,

a consciência sobre a importância da preservação do patrimônio histórico e artístico surge, efetivamente no Brasil, com a mesma finalidade que a fez surgir em outras regiões do mundo. Era o momento em que o Estado pretendia incorporar um ideário de identidade nacional que ao mesmo tempo concedesse 
bases de sustentação junto ao povo brasileiro. Seria uma identidade nacional para um discurso político específico. O objetivo era encontrar tal sustentação na valorização e reconhecimento da cultura nacional a partir de suas raízes mais populares. (RAMOS, 2012).

Acerca disso, curial destacar que por muitos anos, mesmo após a abolição da escravidão, em 1888 com a Lei Áurea, as comunidades afro-descendentes ainda se encontravam à margem da sociedade, haja vista os resquícios do período da escravidão ainda tão presentes naquele povo. Era praticamente inexistente o reconhecimento dos direitos daquele grupo, porém com a evolução constitucional passou-se a observar mais de perto esse grupo étnico e a garantir a preservação das suas memórias culturais, o que verifica-se no seguinte trecho:

o que se percebe com a legislação brasileira para o tema é que esta reflete uma preocupação com a valorização e o reconhecimento de elementos característicos da cultura afro-brasileira à medida que pretende criar mecanismos de preservação da memória desses povos e por conseqüência dessa cultura considerando que privilegia a auto identificação a partir de critérios que remontam a trajetória histórica destes grupos. E através disso contribuir para um processo de conscientização que permita a estes povos e a estas culturas saírem do lugar de descriminados e marginalizados, em que tantas vezes foram colocados. (RAMOS, 2010).

Apesar de legalmente garantido, o direito à propriedade das comunidades quilombolas é apenas o reconhecimento de um direito desse grupo étnico, pois ainda há muito que se fazer para compensar o passado de exclusão, que marcou a história dos afrodescendentes. Acerca disso, é preciso que haja uma transformação nas atitudes da sociedade atual no sentido de incentivar o reconhecimento e a consequente efetivação dos direitos desse grupo, os quais sejam capazes de, ao menos, amenizar essa história de sofrimento marcada pela escravidão.

Assim, o conhecimento desse passado histórico é extremamente importante para que se possa compreender a realidade que, ainda nos dias atuais, essas minorias enfrentam. Portanto, toda essa história faz parte da nossa identidade, visto que os afrodescendentes foram essenciais para a construção da sociedade em que vivemos e, inclusive, para o fomento da economia brasileira.

Por fim, é possível depreender após essa análise acerca da preservação do patrimônio histórico e do reconhecimento da propriedade das comunidades quilombolas, que a inserção dessas medidas no texto constitucional é apenas o primeiro passo, visto que muito há que se fazer sobre essa questão, pois o mais importante, além da preservação de monumentos, documentos históricos e terras de grupos tradicionais, é fazer despertar na sociedade o interesse pela busca do conhecimento dessa história para que a mesma não se perca com o decorrer do tempo.

É, nesse sentido, que o próximo tópico falará acerca da retomada da memória na escola, já que a mesma é formada pelas presentes e futuras gerações, as quais estão prejudicadas, por um lado, pelo fato de não conhecerem de perto a formação histórica de seu próprio país, porém, será por meio 
da preservação do patrimônio histórico, dentre outras medidas apropriadas, que elas terão acesso a essa história, que mesmo com o decorrer do tempo, não ficará perdida.

\section{A formação escolar como locus privilegiado de resgate da memória}

Ao longo da história, a escola exerceu diversos papéis na sociedade a depender das transições sofridas por cada povo, seja na esfera política ou mesmo na social. Para tanto foi preciso realizar uma transformação educacional a fim de adequar a educação ao contexto social vivenciado fora do âmbito escolar e aos anseios de cada povo.

Nesse processo de transformação, buscou-se atender à necessidade de cada geração e, para tanto, foi preciso "a sala de aula transformar-se ela própria em campo de possibilidades de conhecimento dentro do qual há que optar." (SANTOS, 1996, p. 18). Assim, aos alunos foram dadas alternativas às ideias apresentadas, não sendo preciso a adoção de pensamentos que não lhe pertencem, o que é fundamental para a construção de uma consciência crítica.

Deste modo, a escola se apresenta como um espaço de formação, pois ao mesmo tempo em que são ensinados os conteúdos programáticos, é importante que sejam apresentados os problemas sociais vivenciados fora dos muros da escola, os quais apesar de serem conhecidos por grande parte da população não são vivenciados por todos.

De acordo com Freire (1978, p. 90),

não podíamos compreender, numa sociedade dinamicamente em fase de transição, uma educação que levasse o homem a posições quietistas ao invés daquela que o levasse á procura da verdade em comum, "ouvindo, perguntando, investigando". Só podíamos compreender uma educação que fizesse do homem um ser cada vez mais consciente de sua transitividade, que deve ser usada tanto quanto possível criticamente, ou com acento cada vez maior da racionalidade.

Deve-se possibilitar uma ligação entre o que está sendo passado nas salas de aula e o cotidiano desses jovens, o que permitirá o engajamento deles com a teoria. Porém, essa ligação não pode ser desvinculada da retomada dos fatos passados, pois

uma eficiente política de preservação deve ser integrada à comunidade, atingindo a educação em todos os níveis, conscientizando crianças, jovens e adultos da necessidade de manter viva a herança cultural que nossos antepassados nos legaram desde as eras primevas. (MAIA, 2003, p. 41).

Dessa forma, o âmbito escolar deve aproximar o conhecimento teórico da realidade vivenciada pelos alunos, de forma que eles se sintam parte daquele contexto e utilizem o arcabouço teórico adquirido para uma futura transformação social. 
Para que o aluno abandone, por exemplo, a costumeira posição de inércia frente ao que lhe está sendo ensinado, torna-se imprescindível uma educação de crítica e criticizadora (FREIRE, 1978, p. 86), a qual permita que o espaço acadêmico seja marcado por discussões acerca da teoria. O diálogo, por sua vez, é a concretização da postura ativa que deve ser assumida pelos alunos, deste modo, "a dialogação implica na responsabilidade social e política do homem. Implica num mínimo de consciência transitiva [...]" (FREIRE, 1978, p. 70).

Outra causa dessa inércia assumida pelos alunos decorre da incapacidade de indignação dos mesmos, já que eles não estão acostumados a contestarem o que lhes é repassado. Acerca disso, Santos (1996, p. 17) preconiza que o processo de transformação educacional "consiste em recuperar a capacidade de espanto e de indignação e orientá-la para a formação de subjetividades inconformistas e rebeldes."

Nas palavras de Arendt (1997, p. 246), "a aprendizagem volta-se inevitavelmente para o passado, não importa o quanto a vida seja transcorrida no presente." Não se pode permitir, deste modo, uma educação que exclua as memórias acerca das lutas sociais e acontecimentos históricos, que originaram a construção da sociedade atual, pois para que se entenda o atual contexto é necessário o completo conhecimento do passado, haja vista que esse influencia diretamente nas ações contemporâneas.

A construção da memória somente estará completa quando for ultrapassada a fase de escuta de relatos e eles concatenados ao próprio conhecimento a fim de atribuir um sentido à história. É preciso, que a memória seja construída sobre uma base comum e, principalmente, em conjunto para que se evite, por exemplo, a imposição de uma memória oficial, pois como é fornecida pelas autoridades é mais fácil de ser imposta a uma população que encara o passado como um espaço nebuloso e repleto de dúvidas, mas que não é fomentada a buscar a revelação dos acontecimentos.

Ao analisar a história, é possível perceber que muito do que se passa hoje são meras repetições do passado, por isso "só o passado como opção e como conflito é capaz de desestabilizar a repetição do presente." (SANTOS, 1996, p. 17). Nesse sentido, há a importância de conhecer o passado, pois, como enunciado, a sociedade atual terá a possibilidade de escolher entre a repetição das condutas pretéritas ou poderão refutar o que for danoso ao contexto atual. Caso contrário, as gerações futuras não terão como escolher, ou seja, estarão vulneráveis aos arbítrios dos governantes e da própria sociedade.

C contexto escolar passou por diversas transformações nas últimas décadas, como se verifica pela inserção e obrigatoriedade da disciplina de história nos currículos escolares. Ainda, houve a transformação dos métodos de ensino, visto que a educação bancária, tão presente em épocas passadas, foi atenuada, o que permitiu que se começasse a incluir, desta forma, a inclusão dos princípios da educação de emancipação, a qual é proposta por Boaventura de Sousa Santos. Acerca das mudanças protagonizadas pela escola moderna, pode-se afirmar que 
as transformações sociais da contemporaneidade ao mesmo tempo em que reivindicaram por uma escola como local privilegiado de sociabilização, de reprodução dos saberes e fazeres junto as novas gerações, cobram dela a produção de novas relações com o saber acumulado, demandam pela a atualização de seus objetivos e metodologias. (PACHECO, 2010).

Porém, apesar de todas essas inovações, espera-se, ainda, uma mudança mais profunda, a qual necessitará da transformação da postura dos professores, da reconstrução do currículo escolar e, principalmente, da reforma dos conteúdos eleitos para compor a disciplina de história. Estamos falando da inclusão da memória no ambiente escolar, já que se trata de um espaço pouco explorado pelas presentes gerações, o que o torna nebuloso e, portanto, repleto de lacunas a serem preenchidas.

Consoante a essa questão, pode-se afirmar que o problema enfrentado, hoje, para a inserção da memória no ambiente escolar é, segundo Santos (1996, p. 16), a adoção de uma teoria da história responsável por "[...] trivializar, banalizar os conflitos e o sofrimento humano de que é feita a repetição do presente neste fim de século." Desta forma, enquanto os protagonistas do ambiente escolar não derem a devida importância ao resgate da memória por meio de suas disciplinas, o passado continuará sendo vislumbrado pelos próprios alunos e, principalmente, pela sociedade como algo velho e que, por isso, não mais nos interessa.

Ademais, "o sofrimento humano mediatizado pela sociedade de informação está transformado numa telenovela interminável em que as cenas dos próximos capítulos são sempre diferentes e sempre iguais às cenas dos capítulos anteriores." (SANTOS, 1996, p. 16). Acerca disso, pode-se depreender a importância de se revisitar o passado para que a sociedade do presente e do futuro não seja vítima de seu próprio desconhecimento, isso implica dizer que por não conhecer os fatos pretéritos protagonizados pelos antepassados, as presentes e futuras gerações estarão fadadas às repetições, pois não há como evitar aquilo que se desconhece.

De acordo com os ensinamentos do autor, essa trivialização se perfaz pela "morte do espanto e da indignação" (SANTOS, 1996, p. 16), quer-se dizer, com isso, que a sociedade atual se acostumou em aceitar o que lhe é imposto sem se revoltar ou ao menos questionar as atitudes reprováveis praticadas pelos governantes.

Além disso, pode-se afirmar que a tentativa de esquecimento do passado é fortemente defendida por grupos que se sentem ameaçados no caso dos acontecimentos pretéritos virem à tona de forma integral, pois o pouco que já se conhece causa repúdio na sociedade. Porém, a sociedade quer mais do que fragmentos históricos, ou seja, almeja-se uma memória integral muito diferente da que possuímos atualmente, haja vista a fragmentariedade com que nos é contado o passado, tal situação pode ser evidenciada no seguinte trecho:

a desqualificação do passado, como experiência político-social foi absorvida até por grupos influentes de intelectuais que passaram a vê-lo, quase exclusivamente, como um conjunto de discursos dominados por improbabilidades, inverdades, versões e memórias. Instaurou-se o domínio do presenteísmo, como se nisso 
não houvesse perigo das interpretações ideológicas ou construções explicativas descontínuas. (JANOTTI, 2012, p. 43).

Nesse sentido, faz-se "[...] necessária outra teoria da história que devolva ao passado a sua capacidade de revelação, um passado que se reanime na nossa direção pela imagem desestabilizadora que nos fornece do conflito e do sofrimento humano." (SANTOS, 1996, p. 17). Tal medida deverá ter início com a utilização de imagens desestabilizadoras, citadas por Santos, que nos remete às lutas protagonizadas pelas sociedades passadas, por exemplo, as quais iam às ruas contestar os atos arbitrários dos governantes da época e eram fortemente reprimidas pela violência estatal.

Desta forma, não podemos encarar o passado como uma "[...] fatalidade, mas como produto da iniciativa humana" (SANTOS, 1996, p. 17), assim, todo o sofrimento causado aos grupos sociais deve ser relatado para aqueles que não vivenciaram tais momentos históricos a fim de que eles adquiram a capacidade de espanto e indignação frente aos arbítrios enfrentados pelas sociedades passadas, as quais sofreram nas mãos de governantes, que utilizavam o poder para a autopromoção.

Com base nisso, pode-se afirmar que a melhor medida para se adotar nesse processo de inserção da memória na disciplina de história ou mesmo na escola de um modo geral é um trabalho em conjunto para que o interesse dos alunos e dos próprios professores seja despertado, o que pode ser feito por meio da revelação de imagens desestabilizadoras. Tais imagens serão responsáveis por despertar a curiosidade acerca dos fatos que motivaram os acontecimentos pretéritos, os quais marcaram o país e, por isso, fazem parte da nossa identidade.

O grande desafio será, por conseguinte, fazer com que as gerações que não vivenciaram esses acontecimentos se sintam parte desse passado. Isso fará com que elas possuam interesse em conhecer o que se passou, assim como o espírito de indignação, o qual será capaz de motivar a luta contra a repetição daquilo que causou enorme sofrimento aos nossos antepassados. Por isso, é que se deve ter em mente a importância das memórias, já que "o perigo de ignorar o passado público pode também acarretar a perda da visão dialética da História e da vontade política que leva à crítica e à construção de projetos futuros." (JANOTTI, 2012, p. 43).

Nesse sentido, é importante resgatar a função da disciplina de história, a qual é fundamental para a inserção da memória no ambiente escolar, haja vista o fato de que ela

[...] visa contribuir para a formação de um 'cidadão crítico', para que o aluno adquira uma postura crítica em relação à sociedade em que vive. As introduções dos textos oficiais reiteram, com insistência, que o ensino de História, ao estudar as sociedades passadas tem como objetivo básico fazer o aluno compreender o tempo presente e perceber-se como agente social capaz de transformar a realidade, contribuindo para a construção de uma sociedade democrática. (BITTENCOURT, 2012, p. 19).

Desse modo, "a inovação que ocorre quanto aos objetivos é a ênfase atual ao papel do ensino de História para a compreensão do 'sentir-se sujeito histórico' e em sua contribuição para a 
'formação de um cidadão crítico'." (BITTENCOURT, 2012, p. 19). Isso importa dizer que a disciplina de história possui a capacidade de transformar o aluno em um membro do passado histórico, o que será essencial para a construção de um sentimento de pertencimento e, por conseguinte, tornará o educando apto a criticar o que lhe é apresentado nas salas de aula, mas principalmente analisar de maneira crítica o que foi vivido pelas sociedades passadas.

Dessa forma, a missão que propomos não é nem de longe algo fácil de adotar e nem ocorrerá rapidamente, pois se trata de um processo lento e gradual de transformação de interesses, que requer um esforço coletivo de diversas áreas da educação. Porém, é preciso dar início a essa mudança, já que o que se percebe na administração escolar é a adoção do que se considera fácil de ser repassado nas salas de aula a fim de cumprir corretamente o calendário escolar, assim como o currículo adotado. Com base nessa questão, Pacheco (2010) prescreve que

os desafios da sociedade contemporânea cobra dos profissionais da educação, de forma geral, e dos professores de história, de maneira específica, uma revisão críticas dos currículos escolares. A adesão a filosofias idealistas de um mundo redimido pelo desenvolvimento técnico que desqualificam a experiência histórica e o campo social como objeto da investigação científica e racional se mostram como saída fácil e tentadora para os tecnocratas da educação ocupados em reproduzir receituários de uma globalização homogeneizadora e excludente.

Conforme preceituado pelo autor, a disciplina de história tornou-se algo cotidiano e previsível, ou seja, há anos que os mesmos conteúdos são ensinados nas salas de aula e ninguém nunca se questionou acerca dessa seleção, que parece ser um tanto quanto fruto de relações de poder, assim como o currículo. Nesse sentido, "são as relações de poder, [...] as responsáveis pela lógica do que entra ou não no Currículo e, por conseguinte no patrimônio cultural da sociedade." (SILVA, 2012).

É preciso que haja, portanto, uma fundamental contribuição tanto dos historiadores quanto de seus próprios alunos na construção de um currículo adequado, pois o que se espera é uma construção de saberes e nada melhor do que se agrupar variadas visões acerca de um mesmo fato histórico. Tendo em vista que historiadores e alunos compartilham de diferentes experiências, será possível fornecer diferentes interpretações acerca desse passado histórico, o que se tornará em uma importante fonte de saber.

O massacre de índios, desde o período inicial da colonização, a violência contra os negros, as perseguições que ocorreram durante o governo de Getúlio Vargas e os perseguidos políticos do regime militar são alguns exemplos de como a história do Brasil mostra-se atravessada por inúmeros fatos de afronta ao ser humano e que não são relembrados ou são considerados como o preço que se pagou para o progresso.

Tais silenciamentos ou versões parciais da história constituíram-se em obstáculos enormes de resgate da memória, impedindo que as novas gerações pudessem incluir tais memórias em seus 
horizontes de sentido já que foi excluída a possibilidade ampla de simbolização das atrocidades cometidas e de como, nos dias atuais, ainda carregamos a herança de tais atos violentos, que se repetem em diferentes momentos e instâncias sociais.

Neste contexto, surge a necessidade de colocarmos a memória como uma condição para uma ressignificação dos fatos ocorridos no passado. Não se trata de apagar a versão que nos foi passada da história, mas coloca-la como apenas um elemento na arena de narrativas disponíveis, para que as novas gerações possam acessar as várias memórias que marcaram a história do nosso pais. Tal esforço estaria ligado ao que Santos (2010, p. 120) chamou de sociologia das ausências, que busca expandir o domínio das experiências sociais disponíveis, mas que, muitas vezes, estão invisibilizadas.

O autor associa a tal procedimento sociológico um outro, que denominou de sociologia das emergências e complementa:

As duas sociologias estão estreitamente associadas, visto que quanto mais experiências estiverem hoje disponíveis no mundo mais experiências são possíveis no futuro. Quanto mais ampla for a realidade credível, mais vasto é o campo dos sinais ou pistas credíveis e dos futuros possíveis e concretos. Quanto maior for a multiplicidade e diversidade das experiências disponíveis e possíveis (conhecimentos e agentes), maior será a expansão do presente e a contraç̧ão do futuro. (SANTOS, 2010, p. 120).

Com a desinvisibilização de tais memórias, abre-se a possibilidade real para que as novas gerações também possam acessar tais memórias, mesmo não as tendo vivenciado diretamente, mas poderão pautar sua compreensão da realidade em outros elementos e desenvolver uma relação de pertencimento com tais histórias, compreendendo que o presente foi constituído com base também em muito sofrimento humano.

A memória auxiliaria não apenas o olhar para o passado, mas para a análise do presente, ao atribuir significados aos fatos e entender muitos dos avanços (inclusive no campo normativo) que a luta de tantas pessoas fomentou. Com isso, é possível pensarmos na construção de uma consciência coletiva sobre a nossa história.

O fortalecimento da memória constitui um passo fundamental numa sociedade. Tamanha a sua importância que é possível tratá-la como direito fundamental, conforme mencionado acima. Diante da fundamentalidade do direito à memória, é preciso pensar em medidas concretas para a sua efetivação.

É preciso que sejam criados mais espaços para que essas memórias possam ser trazidas ao conhecimento das novas gerações. Para tanto é preciso um projeto educativo mais amplo, desenvolvido em vários espaços sociais, dentre os quais a escola. O que podemos perceber é uma atribuição de grande responsabilidade da escola em ser um espaço privilegiado (já que crianças e jovens passam vários anos em contato direto com ela) para a valorização da memória. Não podemos 
negar a importância do ensino formal em contribuir para este projeto educativo, mas sabemos que ele deve ser pensado de maneira mais ampla, necessitando de inúmeros outros espaços/tempos para que consiga contribuir no processo de conscientização dos indivíduos.

A escola é uma peça fundamental nesta engrenagem que objetiva resgatar a memória. No entanto, não se pode pensar numa escola que, ao contrário, tem servido muito mais para a repetição de uma visão linear da história e com inúmeros silenciamentos quanto a memórias outras que não apenas aquelas que fazem parte da versão oficial.

Para que possamos desenvolver um projeto educativo que tenha efetivamente potencial de favorecer a tomada de consciência, entendemos não ser suficiente apenas a discussão teórica em sala de aula ou a mera leitura dos manuais de história. É preciso uma ampla análise das diversas fontes de onde emanam memórias para que os próprios indivíduos possam ressignificá-las diante do presente em que vivem.

A LDB (Lei n. 9.394/1996) foi alterada pela Lei n. 10.639/2003 instituindo a obrigatoriedade de inserção do estudo da contribuição de diferentes culturas e etnias para a formação do povo brasileiro, especialmente as matrizes indígena, africana e europeia. A norma estabelece que o conteúdo programático a ser desenvolvido inclua o estudo da história da África e dos Africanos, a luta dos negros no Brasil, a cultura negra Brasileira e a contribuição do negro na formação da sociedade nacional.

Salienta também que tais conteúdos sejam ministrados no âmbito de todo o currículo, de maneira transversal (apesar de a lei mencionar que tal conteúdo poderá ser tratado especialmente na área de educação artística, literatura e história). É preciso que tenhamos a clareza de que tornar tal estudo obrigatório, embora represente um avanço enorme, não é condição suficiente para que as abordagens feitas no âmbito do currículo realmente sejam no sentido de valorização e reconhecimento da contribuição do negro ao nosso País.

Vários desafios precisam ser vencidos, como a capacitação de professores, a diversificação de estratégias de ensino que não se limitem a mera aula expositiva, materiais didáticos, etc. $\bigcirc$ critério a ser utilizado para que possamos saber se houve uma boa aprendizagem nesta temática não está ligado à repetição de datas e fatos históricos descontextualizados, mas sim à real possibilidade de produzir nos estudantes o questionamento, a análise e o confronto com a realidade, refletindo sobre as formas de violência que hoje são verificadas e as permanências históricas que podem ser associadas às violências cometidas no passado.

Assim, não adianta que os professores de história apenas se convençam da necessidade de transformação da disciplina, pois para que essa situação seja colocada em prática é preciso que o currículo também seja modificado a fim de atender às exigências da sociedade. Desta forma, não é concebível a adoção de um currículo escolar que não atenda às necessidades dos alunos, tendo em vista que eles são os principais destinatários de tal documento. 
Portanto, será preciso que profundas modificações para se completar a missão de implantar a memória no ambiente escolar, mas a principal delas será despertar o interesse dos alunos e fazer com que os professores acreditem que eles serão capazes de criar a necessidade de busca pela revelação das memórias históricas. Trata-se, desta forma, de um processo lento e gradual de mudança de mentalidade, porém, em um futuro próximo, toda a sociedade entenderá a importância de se conhecer o seu passado e de construir, por conseguinte, a sua identidade nacional.

\section{Considerações finais}

O presente estudo contou com a análise da fundamentalidade da memória aliada à sua previsão na Constituição Federal de 1988 e no ADCT, o que demonstra a preocupação estatal com o seu resgate e, ainda, discutiu-se a função exercida pela memória na formação escolar. Por fim, verificamos as formas pelas quais a memória pode ser resgatada, apresentando, assim, alternativas para a inclusão desse instituto no ambiente escolar.

Torna-se possível afirmar que a memória não representa nem de longe meras lembranças que devem ser deixadas no passado. Pelo contrário, observou-se que esse instituto deve estar presente em todos os momentos e, principalmente, durante a formação escolar, pois é nesse momento da vida que o indivíduo está formando sua consciência crítica e conhecendo as diversas áreas do saber.

A inclusão da memória no ambiente escolar, por sua vez, não deve se resumir na simples inclusão de um conteúdo no programa da disciplina de história, mas deve ir além, no sentido de que os professores incentivem pesquisas tanto acadêmicas quanto fora deste espaço, já que como visto ao longo deste trabalho, a memória encontra-se no patrimônio histórico, em testemunhas vivas de épocas passadas, documentários, registros e nos próprios livros.

Portanto, a memória deve ser inserida no ambiente escolar, mas para tanto será necessário que a própria escola, incluindo professores, diretores e alunos, passe por transformações no sentido de proporcionar tal inclusão, pois todos terão que descobrir juntos o interesse por tal instituto. Assim, todos os protagonistas do processo de aprendizagem deverão estar envolvidos nessa missão, que é a inclusão da memória no ambiente escolar.

\section{Referências}

ABREU, Martha; MATTOS, Hebe. Remanescentes das Comunidades dos Quilombos: memória do cativeiro, patrimônio cultural e direito à reparação. 2012. Disponível em: http://www.snh2011.anpuh. org/resources/anais/14/1299778862_ARQUIVO_anpuh2011.pdf 2012. Acesso em: 15 out. 2015.

ARENDT, Hannah. Entre o passado e o futuro. 4. ed. São Paulo: Perspectiva, 1997. 
BARBOSA, Marco Antônio Rodrigues; VANNUCHI, Paulo. Resgate da memória e da verdade: um direito de todos. In: SOARES, Virgínia Prado; KISHI, Sandra Akemi Shimada (org.). Memória e verdade: a justiça de transição no Estado Democrático brasileiro. Belo Horizonte: Fórum, 2009. p. 55-67.

BICUDO, Hélio; PIOVESAN, Flávia. Direito à verdade e à justiça? Folha de São Paulo, São Paulo, 2 dez. 2006. Disponível em: http://www1.folha.uol.com.br/fsp/opiniao/fz0212200609.htm. Acesso em: 16 jul. 2017.

BITTENCOURT, Circe. Capitalismo e cidadania nas atuais propostas curriculares de história. In: BITTENCOURT, Circe. O saber histórico na sala de aula. 12. ed. São Paulo: Contexto, 2012. p. 11-27.

BRASIL. Constituição: República Federativa do Brasil de 1988. Brasília, DF: Senado Federal, 1988.

DANTAS, Fabiana Santos. Direito fundamental à memória. Curitiba: Juruá, 2010.

DIMOULIS, Dimitri; MARTINS, Leonardo. Teoria geral dos direitos fundamentais. 3. ed. rev., atual e ampl. São Paulo: Revista dos Tribunais, 2011.

FREIRE, Paulo. Educação como prática da liberdade. 8. ed. Rio de Janeiro: Paz e Terra, 1978.

JANOTTI, Maria de Lourdes Monaco. Histórica, política e ensino. In: BITTENCOURT, Circe (org.). O saber histórico na sala de aula. 12. ed. São Paulo: Contexto, 2012. p. 42-53.

LAKATOS, Eva Maria; MARCONI, Marina de Andrade. Metodologia Científica. 4. ed. São Paulo: Atlas, 2004.

MAIA, Felícia Assmar. Direito à memória: o patrimônio histórico, artístico e cultural e o poder econômico. Movendo Idéias, Belém, v. 8, n. 13, jun. 2003. Disponível em: http://www.nead.unama. br/site/bibdigital/pdf/artigos_revistas/214.pdf. Acesso em: 3 jul. 2017.

OST, François. O tempo do direito. São Paulo: Edusc, 2005.

PACHECO, Ricardo de Aguiar. Os saberes da história: elementos para um currículo escolar contemporâneo. Antíteses, Londrina, v. 3, n. 6, p. 759-776, jul./dez. de 2010. Disponível em: < http:// www.uel.br/revistas/uel/index.php/antiteses >. Acesso em: 28 out. 2012.

PIRES, Cecília Maria Pinto. Memória, verdade e justiça como ética. Pensar, Fortaleza, v. 20, n. 1, p. 61-83, jan./abr. 2015.

RAMOS, Leila Martins. Comunidades quilombolas no Brasil diante das políticas de patrimônio cultural brasileiro. Revista África e Africanidades, ano 3, n. 9, maio 2010. Disponível em: http:// www.africaeafricanidades.com/documentos/Comumidades_quilombolas_Brasil.pdf. Acesso em: 28 jul. 2017.

SAMPAIO, José Adércio Leite; ALMEIDA, Alex Luciano Valadares. Verdade e história: por um direito fundamental à verdade. In: SOARES, Virgínia Prado; KISHI, Sandra Akemi Shimada (org.). Memória e verdade: a justiça de transição no Estado Democrático brasileiro, Belo Horizonte: Fórum, 2009. p. 249-271.

SANTOS, Boaventura de Sousa. A gramática do tempo: para uma nova cultura política. 3. ed. São Paulo: Cortez, 2010. 
SANTOS, Boaventura de Sousa. Para uma pedagogia do conflito. In: SILVA, Luiz Heron da; AZEVEDO, José Clóvis de; SANTOS, Edmilson Santos (org.). Novos mapas culturais, novas perspectivas educacionais. Porto Alegre: Sulina, 1996. p. 15-33.

SILVA FILHO, José Carlos Moreira da. O anjo da história e a memória das vítimas: o caso da ditadura militar no Brasil. Veritas, Porto Alegre, v. 53, n. 2, p. 150-178, abr./jun. 2008.

SILVA, Maria de Fátima Barbosa da. A construção de uma memória identitária através do currículo. 2012. Disponível em: http://www.encontro2010.rj.anpuh.org/resources/anais/8/1276553027_ARQUIVO_simptemcurrimemoria.pdf. Acesso em: 20 ago. 2017.

ORGANIZAÇÃO DAS NAÇÕES UNIDAS PARA A EDUCAÇÃO, A CIÊNCIA E A CULTURA. Convenção de Haia de 1954. Disponível em: http://www.unesco.org/culture/natlaws/media/pdf/ bresil/brazil_decreto_44851_11_11_1958_por_orof.pdf. Acesso em: 6 ago. 2017. 